\title{
Memória e patrimônio documental: a experiência no tratamento arquivístico do acervo da UFV sob guarda do Arquivo Central e Histórico da UFV
}

\author{
Aline Maria de Aguiar da Silva ${ }^{1}$,Vanessa Cerqueira \\ Teixeira ${ }^{2}$, Fernando Altoé ${ }^{3}$, Nathan Moreira Fioresi ${ }^{4}$, \\ Fábio Adriano Hering ${ }^{5}$ Eduardo Luiz dos Santos ${ }^{6}$
}

Resumo: Este trabalho tem por objetivo relatar a experiência com o tratamento e organização do acervo documental sob posse do Arquivo Central e Histórico da UFV, que congrega uma vasta documentação relativa à trajetória da Universidade, desde sua fundação em 1926 até os dias atuais. A partir do trabalho de extensão, foram desenvolvidas atividades de conservação preventiva do acervo, além de possibilitar um espaço de interlocução entre teoria e prática histórica.

Palavras chave: Arquivo Central e Histórico da UFV, conservação documental, memória institucional.

Áreas temáticas: Comunicação, cultura e educação.

\section{Memory and documentary heritage: the experience in the treatment of archival collection of UFV under guard of the Arquivo Central e Histórico da UFV}

Abstract: This work aims to report an experience with treatment and organization of the document collection in Arquivo Central e Histórico da UFV, which brings a large amount of documents about the history of the University since its foundation in 1926 until the present day. With this extension work was developed preventive conservation activities of the heap, besides providing a space for dialogue between theory and historical practice.

Keywords: Arquivo Central e Histórico da UFV, documents conservation, institutional memory.

\footnotetext{
${ }^{1}$ Universidade Federal de Viçosa, Graduanda em História e bolsista PROEXT. E-mail: aline.aguiar@ ufv.br

2 Universidade Federal de Viçosa, Graduanda em História e bolsista PROEXT. E-mail: vanessa. teixeira@ufv.br

3 Universidade Federal de Viçosa, Graduando em História e bolsista PROEXT. E-mail: fernando. altoe@ufv.br

4 Universidade Federal de Viçosa, Graduando em História e bolsista PROEXT. E-mail: nathan fiorese@ufv.br

5 Universidade Federal de Viçosa, Coordenador do DHI, do ACH e do Programa "Patrimônio Documental e Memória da Zona da Mata Mineira: Conservação Preventiva, Digitalização e Acesso Virtual dos Acervos da ESAV e do Fórum de Viçosa" (PROEXT - Edital 2013). E-mail: fahering@ufv.br ${ }^{6}$ Universidade Federal de Viçosa, Arquivista responsável pelo Arquivo Central Histórico da UFV e supervisor das atividades previstas no Proext - Edital 2013. E-mail: eduardo.santos@ufv.br
} 


\section{Memoria y patrimonio documental: la experiencia en el tratamiento de la colección de archivos de la UFV guardia bajo el Arquivo Central e Histórico da UFV}

Resumen: Este trabajo pretende aportar una experiência con el tratamento y organización de la colección de documentos em poder del Arquivo Central e Histórico da UFV, que aporta uma amplia documentación de la historia de la Universidad desde su fundación em 1926 hasta la actualidad. A partir de este trabajo fueram desenvolvidas atividades de conservación preventiva del acervo, proporcionando um espacio para el diálogo entre la teoria y la práctica histórica.

Palabras clave: Arquivo Central e Histórico da UFV, documental conservación, memoria institucional.

\section{Introdução}

O presente trabalho é o resultado de atividade desenvolvida pelos alunos engajados no "Programa Patrimônio Documental e Memória da Zona da Mata Mineira: Conservação Preventiva, Digitalização e Acesso Virtual dos Acervos da ESAV, Fórum de Viçosa e Casa Setecentista de Mariana”, aprovado pelo PROEXT 2013, que objetiva desenvolver sistemas de informação e de preservação documental que permitam resguardar o Patrimônio Cultural Brasileiro, em especial arquivos de relevância histórica e cultural em poder de instituições públicas, dos efeitos degradantes causados pelo acondicionamento inadequado ou pelo contato direto e manuseio do papel. O Programa busca dar à comunidade acesso a estas bases documentais, através de imagens digitais armazenadas em bancos de dados em bases digitais, por meio da rede mundial de computadores (em uma etapa mais adiantada do processo). Como parte desse programa, apresenta-se aqui parte do trabalho que vem sendo desenvolvido no Arquivo Central e Histórico da UFV (ACH-UFV). É importante ressaltar que esse trabalho vem contribuindo sobremaneira para a chamada "zona silenciosa da historiografia" de Minas Gerais, tornando possível que novas pesquisas frutifiquem sobre a região de Viçosa, especialmente a atual Universidade Federal de Viçosa (1969 até o presente) e as instituições de Ensino que a formaram historicamente, a saber: ESAV (1926-1948) e UREMG (1948-1969)

O Arquivo Central e Histórico da UFV (ACH-UFV), vinculado ao Departamento de História, foi criado na década de 1980 com o intuito de organizar, preservar e divulgar a memória da Universidade, possuindo atualmente ampla documentação que abrange os três períodos constitutivos da Instituição: ESAV, UREMG e UFV. Em sua fase inicial, o ACH-UFV esteve vinculado à Divisão de Assuntos Culturais e contou com o empenho fundamental do professor José Marcondes Borges na estruturação do Arquivo e na preservação da memória da Instituição. Esse acervo esteve localizado durante certo tempo no subsolo do Edifício Arthur Bernardes e em depósitos de departamentos e órgãos da Universidade, não recebendo acondicionamento adequado. Por isso, as atividades levadas adiante pelo Programa encontraram no seu acervo uma forma de realizar sua função 
social ao mesmo tempo em que forma os novos pesquisadores e especialistas em preservação documental. As tarefas ali realizadas são primordialmente: higienização dos documentos, levantamento de dados, organização física e conservação preventiva da documentação, construção de guias de acesso ao acervo e criação de um banco de dados eletrônico.

Tenha-se em conta que a preservação da memória institucional é o fio condutor das metas de organização do acervo referente à Universidade levadas adiante pelo ACH-UFV, e é com essa documentação que a equipe tem trabalhado. Com documentos de valor histórico e documentos intermediários que ainda podem ser utilizados pelos setores administrativos da Universidade, o ACH-UFV conserva uma parte da história educacional brasileira através de suas fontes primárias, assumindo grande importância como fonte de pesquisa. O acervo textual do ACH-UFV consta de três fundos documentais correspondentes a cada fase da Instituição, além da coleção de jornais de circulação local, regional e nacional, como também da coleção de fotografias da cidade de Viçosa e da Universidade.

Atualmente o ACH-UFV conta com a administração do arquivista Eduardo Luiz dos Santos, com a coordenação do professor Fábio Adriano Hering e com uma equipe de catorze bolsistas, vinculados aos cursos de História, Ciências Sociais e Secretariado Executivo Trilíngue. Dentre os bolsistas, alguns possuem vínculo voluntário, outros são da bolsa manutenção ${ }^{7}$ (proporcionada pela própria Universidade) ou estão ligados a projetos de extensão ${ }^{8}$. O que se procura relatar a seguir são as tarefas desempenhadas desde o início de 2012 e os desafios e dificuldades enfrentados, expondo também os resultados preliminares e as experiências acadêmicas e de extensão desenvolvidas naquele espaço por parte da equipe do Programa que vem trabalhando no ACH-UFV.

\section{A importância da extensão para o desenvolvimento das atividades no ACH-UFV}

O Programa "Patrimônio Documental e Memória da Zona da Mata Mineira: Conservação Preventiva, Digitalização e Acesso Virtual dos Acervos da ESAV, Fórum de Viçosa e Casa Setecentista de Mariana" foi fundamental para o início das atividades de tratamento arquivístico ao acervo documental do ACH-UFV. O acervo trabalhado é composto, em sua grande parte, por documentos textuais manuscritos e impressos de caráter administrativo. Tais documentos registram as mudanças ocorridas na Instituição, os vínculos estabelecidos com outras universidades, empresas nacionais e internacionais, além de documentos referentes a assentamentos de professores, processos administrativos e seletivos, relatórios técnicos, correspondências, monografias, artigos científicos e outras publicações, como a Revista Ceres, que ainda hoje é publicada. O contato com essa vasta documentação está possibilitando-nos conhecer de forma mais profunda a história da Universidade através de suas fontes primárias, aguçando, portanto, a prática com os documentos, o que corresponde ao próprio ofício do historiador. Essa experiência é enriquecedora para acadêmicos do curso 
de História, uma vez que se tem a oportunidade de transcender a teoria das salas de aula e aprender na prática aquilo que é o trabalho do historiador: produzir conhecimento sobre o passado a partir dos registros documentais disponíveis. Nesse sentido, para que os documentos não se percam e estejam à disposição do historiador, é imprescindível sua preservação. Dessa forma, além de lidar diretamente com os registros primários da Universidade e, de certa forma, produzir conhecimento sobre a Instituição, a meta maior no ACH-UFV é preservar os documentos para divulgar a toda comunidade. $\mathrm{O}$ trabalho diário consiste em descrever toda a documentação dos fundos no intuito de preservar a memória institucional.

O mapeamento do acervo do ACH-UFV consistiu em localizar espacialmente a documentação da casa em que funciona o Arquivo. Buscou-se então enumerar as salas, as estantes e as caixas com o objetivo de facilitar o acesso à documentação. O próximo passo foi o levantamento da massa documental, que ainda está em processo de desenvolvimento. Este processo consiste em abrir cada caixa e descrever todos os seus documentos. (Fig. 1) Promove-se, assim, a descrição da massa documental através da construção de fichas, que são elaboradas de acordo com as informações expressas nos documentos. Para cada caixa há uma ficha onde é registrado todo conteúdo dos documentos relativos àquela caixa, além de sua localização espacial. Essas informações são lançadas num banco de dados eletrônico, no qual se acrescenta, além das informações já elencadas, a separação em cores correspondentes a cada período da Instituição: vermelho (ESAV), amarelo (UREMG) e cinza (UFV), o que facilita a utilização do banco de dados pelo pesquisador. Até abril de 2013, cercade 56\% do acervo foi identificado e organizado através deste instrumento de pesquisa provisório, gerando um controle topográfico do acervo para ser posteriormente classificado, segundo as normas estabelecidas pelo Conselho Nacional de Arquivos - Conarq (BRASIL, 2001).

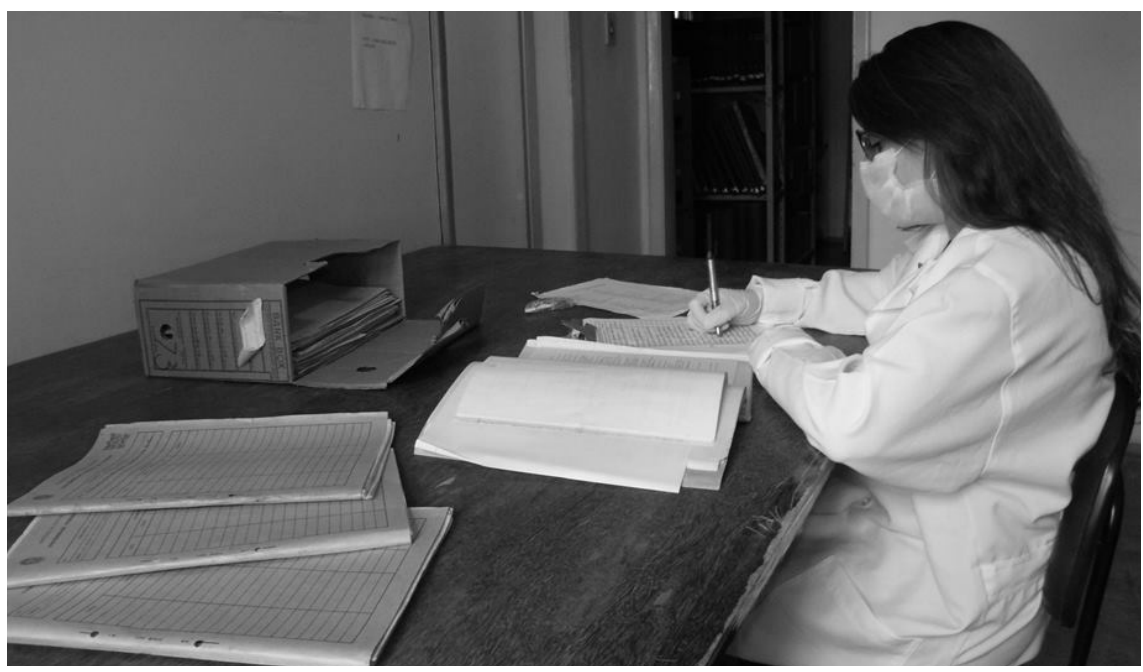

Fig. 1 - Estagiária descrevendo documentos textuais no ACH-UFV.

Foto: Eduardo Luiz dos Santos. 
A classificação visa atribuir códigos aos documentos com o objetivo de estabelecer um nível de organização uniforme, consolidando dessa forma um padrão adequado às necessidades do Arquivo; além disso, essa classificação promove uma ligação entre a documentação quanto à sua tipologia e o seu assunto. A classificação busca também otimizar o processo de localização do documento no acervo (GONÇALVES, 1988). Após a etapa de classificação, pretende-se criar um inventário, elaborado a partir dos parâmetros da NOBRADE. Portanto, o Programa está possibilitando não só a organização e a difusão do acervo da UFV para a comunidade acadêmica e viçosense, como também auxiliando a formação da equipe, ao proporcionar a interlocução entre as práticas arquivística e de pesquisa histórica, muitas vezes alienada uma da outra.

\section{O guia e a divulgação do arquivo}

Através do controle topográfico do acervo, resultado do instrumento de pesquisa provisório em andamento, foi possível estruturar o Guia. Segundo a teoria arquivística, o Guia é preferencialmente o primeiro instrumento de pesquisa a ser produzido por um arquivo, já que ele permite um mapeamento panorâmico do acervo e contém as informações básicas referentes à instituição responsável por sua administração. Todo Guia possui um padrão para sua elaboração que consta de duas fases distintas: a primeira parte traz informações gerais da instituição, além de informações práticas como endereço ou condições de consulta; a segunda etapa tem por objetivo descrever os fundos e coleções do arquivo, cuja finalidade é levar ao conhecimento do pesquisador a documentação sob posse do arquivo (LOPES, 2002).

A primeira parte do Guia do ACH-UFV consta dos seguintes elementos: o nome da instituição, endereço, telefone para contato, dias e horários de funcionamento, condições de acesso, estrutura administrativa, histórico da instituição, origem da documentação, restrições ou não à consulta, suporte e tecnologia existentes à disposição do pesquisador para uso e condições de reprodução dos documentos. Ressaltamos que este guia será disponibilizado brevemente para acesso onlineefoi apresentado em forma de artigo no I Simpósio Internacional de História Pública, ocorrido em 2012 na Universidade de São Paulo e encontra-se disponível no próprio ACH-UFV (ARAÚJO, 2012).

Para a confecção da primeira etapa do Guia, utilizamos como referência a Norma Internacional para Descrição de Instituições com Acervo Arquivísitico (ISDIAH, 2012). Segundo a Norma, três campos são indispensáveis para a apresentação de uma instituição de arquivo: o primeiro é o identificador, que corresponde ao código que reconhece o arquivo. No caso específico do ACH-UFV: "BR ACH-UFV". O segundo campo é a forma autorizada de nome e a quem o arquivo está vinculado: Arquivo Central e Histórico da UFV, vinculado ao Departamento de História. O terceiro e último campo corresponde ao endereço e aos dados práticos para a localização do órgão. O ACH-UFV está localizado na Villa Gianetti, Casa 10, no Campus Universitário. Para a elaboração da segunda parte do Guia, o acervo 
foi dividido em cinco fundos/coleções documentais: ESAV, UREMG, UFV, ACERVO FOTOGRÁFICO DO ARQUIVO CENTRAL E HISTÓRICO DA UFV e JORNAIS DO BRASIL. As fotografias e os jornais encontram-se em melhores condições de pesquisa, já que as fases de limpeza e classificação estão bem adiantadas, e em alguns casos até mesmo concluídas.

Como se percebe, a construção do Guia do ACH-UFV leva em conta a documentação específica do Arquivo, e sua construção só é possível a partir do conhecimento que se tem do acervo, sendo que este conhecimento se dá a cada dia através do contato direto com a documentação. Com o resultado das atividades, consegue-se descrever parte do acervo e dos principais fundos documentais. A próxima fase será a classificação, fundamental para a elaboração dos demais instrumentos de pesquisa, como os inventários. Avalia-se ter obtido um resultado satisfatório até o momento, pois o Guia é uma das ferramentas mais indicadas para divulgar uma instituição de arquivo, sendo no caso específico, o ACH-UFV e seus fundos documentais, além de colaborar na organização de toda a documentação, proporcionar qualidade à gestão documental e garantir o acesso à informação. Além disso, todos os instrumentos construídos e planejados já nascem com estrutura favorável à sua possível divulgação virtual, visto que esse é um dos objetivos da NOBRADE.

\section{Os fundos ESAV, UREMG e UFV}

Como já dito, os três grandes fundos documentais sob guarda do ACH-UFV são os da ESAV, UREMG e UFV. Esta divisão obedece às três fases constitutivas da Universidade e cada fundo congrega um manancial de informações relativas ao Ensino, Pesquisa e Extensão da UFV. Além destes três fundos textuais, há ainda duas coleções, uma de jornais e outra de fotografias. Contudo, focar-se-á somente nos documentos textuais, considerando que o PROEXT (Editais 2011, 2012 e 2013) contempla em seu programa somente os documentos desta natureza.

A divisão dos fundos documentais só foi possível mediante levantamento da massa documental. Ao encontrar documentos dos três períodos da Universidade, chegou-se à conclusão de que a melhor forma de organizar o acervo textual seria dividi-lo conforme as mudanças cronológicas e estruturais pelas quais passou a Instituição ao longo de sua trajetória. Essa divisão, contudo, não acontece em sua forma física, ou seja, não se separa os documentos correspondentes à ESAV, UREMG ou UFV em caixas ou salas diferentes. Respeita-se à forma como os documentos encontram-se dispostos nas caixas e sua separação física ocorre após a etapa classificatória. No entanto, no momento em que são descritos os documentos nas fichas e são migrados os dados para uma planilha do programa Excel, cores diferentes são atribuídas para indicar se o documento é da ESAV, UREMG ou UFV.

Os documentos referentes à ESAV remontam desde antes da fundação da Escola, em 1926. Do período de 1926 a 1948 foram encontrados documentos relativos às atividades da Instituição, como documentos de cunho administrativo e ligados ao ensino, pesquisa e extensão. 
Deste mesmo período, foi encontrada uma quantidade significativa de documentos manuscritos, escritos, por exemplo, por Arthur Bernardes ou João Carlos Bello Lisboa, primeiros diretores da ESAV. No decurso da organização dos documentos da ESAV, o próprio espaço físico do ACH-UFV foi sendo reorganizado. Dessa forma, diversas caixas que se encontravam mal dispostas foram realocadas num novo acondicionamento. Ao longo do andamento das atividades, foi encontrada uma vasta documentação referente aos históricos escolares da ESAV e da UREMG, o que veio trazer contribuições no que tange ao conhecimento dos cursos que eram oferecidos à época. Todos esses diários de classe foram higienizados, separados e acondicionados obedecendo à sua cronologia, e atualmente estão bem mais acessíveis ao manuseio do pesquisador.

Com relação aos fundos da UREMG e UFV, os documentos estão passando pelo mesmo processo de higienização e organização, com a abertura das caixas e sua descrição. Do período da UREMG, encontrou-se uma vasta documentação referente à Pós-Graduação, uma marca deste período. Vale ressaltar que uma grande quantidade de documentos referentes a este período está em inglês, visto que à época a Universidade Rural do Estado de Minas Gerais firmou diversos convênios com instituições estrangeiras visando à instalação de cursos ao nível de Pós-Graduação. Esses documentos serão traduzidos por estudantes do curso de Secretariado Executivo Trilíngue ${ }^{9}$, possibilitando sua difusão à comunidade acadêmica.

\section{Considerações finais}

A prática no Arquivo Central e Histórico da UFV, como um projeto de extensão, tem sido de uma riqueza incomensurável. As atividades desenvolvidas a partir do PROEXT têm possibilitado o contato direto com uma rica documentação que registra a história da UFV desde a sua fundação até os dias atuais. $\mathrm{O}$ trabalho com os documentos produzidos pela Instituição ao longo de sua trajetória está sendo fundamental à formação acadêmica dos bolsistas, uma vez que eles têm contato direto com esses registros que guardam a memória da Instituição.

Além do aprendizado diário sobre técnicas arquivísticas, o trabalho tem como objetivo maior a preservação da memória da UFV contida nos documentos. Por isso, têm sido realizadas atividades como higienização, levantamento da massa documental, classificação, melhoria no acondicionamento dos documentos, criação de banco de dados, etc., tudo para garantir ao documento um tratamento correto e, consequentemente, sua melhor difusão a toda comunidade que desejar fazer pesquisas e produzir conhecimento.

O extensionista em formação no ambiente do ACH-UFV tem tido a oportunidade de conquistar novos conhecimentos devido às práticas e atividades ali desenvolvidas, encontrando um universo prático com o qual os saberes teóricos podem dialogar. De igual importância tem também sido a troca diária de conhecimento entre os bolsistas e voluntários, que convivem no espaço do Arquivo trocando experiências e contribuindo para a construção de um projeto maior. Desta forma, o ACH-UFV também 
se beneficia com as atividades desenvolvidas, visto que a construção dos instrumentos de pesquisas está contando com a colaboração de futuros profissionais diretamente ligados à necessidade de consulta e constante pesquisa em acervos documentais, instrumentos que potencializam, através do acesso às informações, o desenvolvimento de pesquisas e a difusão da memória institucional, colocando o ACH-UFV como verdadeiro setor responsável por salvaguardar a história da UFV, que muito contribui para composição da história da educação brasileira.

\section{Notas:}

7. O nome desta modalidade de bolsa foi alterado no Edital 2013 para "Bolsa de Iniciação Profissional".

8. No ano de 2013 o Arquivo Central e Histórico da UFV foi contemplado com os projetos "Documentos da Universidade Rural do Estado de Minas Gerais (UREMG): organização, preservação e difusão cultural do acervo textual do Arquivo Central e Histórico da Universidade Federal de Viçosa" (PROCULTURA), e com o projeto "Jornais do Brasil: O arquivo Central e histórico da UFV na preservação e acesso da informação" (FURNABEX), ambos coordenados pela professora Patrícia Vargas Lopes de Araújo.

9. As traduções serão realizadas por um bolsista através do projeto "Tradução e organização de documentos históricos que demonstrem a colaboração de instituições norte-americanas para a criação da pós-graduação"(PIBEX), coordenado pela Professora Rosália Beber de Souza.

\section{Referências Bibliográficas}

ARAÚJO, P.V.L.; SANTOS, E.L. Construção de instrumentos de pesquisa do Arquivo Central e Histórico da Universidade Federal de Viçosa: difusão da história, salvaguarda da memória. In: I Simpósio Internacional De História Pública, 2012, São Paulo. Anais... São Paulo: USP, 2012.

BRASIL, Arquivo Nacional. Conselho Nacional de Arquivos: classificação, temporalidade e destinação de documentos de arquivo; às atividades meio da administração pública/Arquivo Nacional. Rio de Janeiro: Arquivo Nacional, 2001.

GONÇALVES, J. Como classificar e ordenar documentos do arquivo. Vol 2. São Paulo: Arquivos do Estado, 1998.

ISDIAH: Norma internacional para descrição de instituições com acervo arquivísitico. Conselho Internacional de Arquivos; Trad. de Vitor Manoel Marques da Fonseca. Rio de Janeiro: Arquivo Nacional, 2009.

LOPES, A.P.A. Como descrever documentos de arquivo: elaboração de instrumentos de pesquisa. São Paulo: Arquivo do Estado, Imprensa Oficial, 2002. 